\title{
Evaluation of Aluminium Complexation Reaction for Flavonoid Content Assay
}

\author{
Anna Pękal • Krystyna Pyrzynska
}

Received: 28 November 2013 / Accepted: 22 January 2014 / Published online: 11 February 2014

(C) The Author(s) 2014. This article is published with open access at Springerlink.com

\begin{abstract}
Two widely applied spectrophotometric assays based on aluminium complex formation used for determination of total flavonoid content in food or medicinal plant samples were examined for several compounds from different classes of flavonoid family. The method which involves the measurement at $410-430 \mathrm{~nm}$ after addition of $\mathrm{AlCl}_{3}$ solution is selective only for flavonols and flavones luteolin. The procedure in the presence of $\mathrm{NaNO}_{2}$ in alkaline medium seems to be specific for rutin, luteolin and catechins, but also phenolic acids exhibit considerable absorbance at $510 \mathrm{~nm}$. Application of both procedures to natural samples gave different order in terms of their flavonoid content. Thus, the expression "total flavonoid" content is not adequate as the results of both methods are dependent on the structure of the individual flavonoids present.
\end{abstract}

Keywords Total flavonoid · Aluminium chloride reaction · Quantitative determination

\section{Introduction}

The spectrophotometric assay based on aluminium complex formation is one of the most commonly used procedure for the so-called total flavonoid determination, as the content of these compounds is considered as an important parameter for evaluating food or medicinal plant samples. This method, proposed initially by Christ and Müller (1960) for the analysis of herbal materials, was latter several times modified. Careful research in literature indicated variation in experimental conditions upon application of Al-flavonoid complexation reaction. Table 1 shows a short overview of literature studies employing this

A. Pękal $\cdot$ K. Pyrzynska $(\bowtie)$

Department of Chemistry, University of Warsaw, Pasteura 1, 02-093 Warsaw, Poland

e-mail: kryspyrz@chem.uw.edu.pl reaction for evaluation of "total flavonoid" content in different kinds of samples. Two widely applied procedures can be distinguished. In the first one, $\mathrm{AlCl}_{3}$ solution in the concentration range of $2-10 \%(\mathrm{~m} / \mathrm{v})$ is added to a sample and can be applied in the presence of acid or acetate solution; in some cases, only methanol or water is added. Measurements were done after 2 $60 \mathrm{~min}$ of the addition of $\mathrm{AlCl}_{3}$ at $404-430 \mathrm{~nm}$ and different flavonols (quercetin, rutin, quercetrin, galangin) as well as flavan-3-ol catechin were used as the standard compounds for the expression of results. In the second often used procedure, complexation reaction is carried out in the presence of $\mathrm{NaNO}_{2}$ in alkaline medium, which was applied in the past for the determination of $o$-diphenols (Barnum 1977). The method is based on the nitration of any aromatic ring bearing a catechol group with its three or four positions unsubstituted or not sterically blocked. After addition of Al(III), a yellow solution of complex was formed, which then turned immediately to red after addition of $\mathrm{NaOH}$, and the value of absorbance is measured at $510 \mathrm{~nm}$. Catechin is preferred as a standard compound in this procedure (Table 1). The authors of the published papers did not explain why they chose the proper procedure for the evaluation of flavonoid content in natural samples.

In the present study, a critical examination of these two procedures was conducted with respect to reaction media as well as to the compounds from different classes of flavonoid family. The 13 flavonoids selected for this study are the most common and abundant in plants. The observation and suggestions was then tested for several commercial samples.

\section{Materials and Methods}

Chemicals and Samples

The commercial standards of phenolic compounds were purchased from Sigma-Aldrich (Steinheim, Germany). The 
Table 1 Examples of studies employing chelation with Al(III) for evaluation of total flavonoid content

\begin{tabular}{lllllll}
\hline Sample & $\mathrm{Al}(\mathrm{III})$ solution & Medium & Time, min & $\lambda_{\text {max }}, \mathrm{nm}$ & Standard compound & Ref. \\
\hline Herb preparation & $10 \%$ & 1 drop of $\mathrm{HCl}$ & 40 & 404 & Rutin & Matyuschenko and Stepanova 2003 \\
Propolis & $2 \%$ & Glacial $\mathrm{CH}_{3} \mathrm{COOH}$ & 30 & 415 & Galangin & Cvek et al. 2007 \\
Herbs & $2 \%$ & - & 60 & 420 & Quercetrin & Ordonez et al. 2006 \\
Herbs & $1.5 \%$ & - & 2 & 415 & Quercetrin & Chen et al. 2007 \\
Oregano & $2 \%$ & - & 10 & 430 & Rutin & Licina et al. 2013 \\
Aronia & $10 \%$ & $\mathrm{CH}_{3} \mathrm{COOK}$ & 30 & 415 & Quercetin & Horszwald et al. 2013 \\
Fruits & $2 \%$ & - & 10 & 415 & Catechin & Praveen and Awang 2007 \\
Herb extract & $10 \%$ & $\mathrm{CH}_{3} \mathrm{COOK}$ & 30 & 415 & Rutin & Gouveia and Castilho 2011 \\
Herbs & $0.1 \mathrm{M}$ & $\mathrm{CH}_{3} \mathrm{COOK}$ & 20 & 410 & Rutin & Zhang et al. 2013 \\
Tea & $25 \mathrm{~g} / \mathrm{L}$ & $\mathrm{CH}_{3} \mathrm{COONa}_{20}$ & 15 & 430 & Rutin & Cimpoiu et al. 2011 \\
Honey & $10 \%$ & $\mathrm{NaNO}_{2}+\mathrm{NaOH}$ & 11 & 510 & Quercetin & Mãrghitas et al. 2009 \\
Wines & $1 \%$ & $\mathrm{NaNO}_{2}+\mathrm{NaOH}$ & 5 & 510 & Catechin & Ivanova et al. 2010 \\
Ginger & $10 \%$ & $\mathrm{NaNO}_{2}+\mathrm{NaOH}$ & 10 & 430 & Quercetin & Ghasemzadeh et al. 2010 \\
Cabbage & $10 \%$ & $\mathrm{NaNO}_{2}+\mathrm{NaOH}$ & 6 & 510 & Quercetin & Jaiswal and Abu-Ghannam 2013 \\
Herbs & $10 \%$ & $\mathrm{NaNO}_{2}+\mathrm{NaOH}$ & 5 & 510 & Quercetin & Eghdami and Sadeghi 2010 \\
\hline
\end{tabular}

standards were dissolved in methanol (Merck). All other common reagents were of the appropriate purity from various suppliers. Ultrapure water from Milli-Q system (Millipore, Bedford, USA) with conductivity of $18 \mathrm{MQ}$ was used in all experiments.

The commercial samples were purchased from a local market. It includes the following: red wine (Cabernet Sauvignon, Chile, 2011), orange and apple juices (Tarczyn, Poland), teas Yellow Label (black tea), Delight Citrus (fruit tea) and Green Tea Indonesia (all Lipton brand) as well as herbs St. John's wort (Hypericum perforatum) and chamomile (Matricaria chamomilla L.) from Herbapol (Poland).

The tea bags $(1.5-2 \mathrm{~g})$ were dipped into $100 \mathrm{~mL}$ of freshly boiled water for $10 \mathrm{~min}$ to represent the typical quantity consumed by tea drinkers. After the infusion time, the bags were removed and the partially turbid solutions were filtered after cooling to room temperature. The samples were diluted with water to the concentrations appropriate for spectrophotometric measurements.

\section{Procedures for Flavonoid Content}

The flavonoid content was determined according to two mostly applied spectrophotometric methods based on the formation of aluminium-flavonoid complexes. All analyses were carried out in triplicate.

Procedure 1: An aliquant of $\mathrm{AlCl}_{3}$ solution $(0.5 \mathrm{~mL}$, $2 \%, w / v)$ was added to $1 \mathrm{~mL}$ of the test solution (standard or sample) and subsequently $0.5 \mathrm{~mL}$ of water, $\mathrm{HCl}, \mathrm{CH}_{3} \mathrm{COONa}$ or $\mathrm{CH}_{3} \mathrm{COONH}_{4}$ (each at concentration of $1 \mathrm{M}$ ) was added. The concentrations of standard solutions of flavonoids were $100 \mu \mathrm{M}$. The mixture was vigorously shaken and then after 10 min of incubation at room temperature, subjected to spectral analysis in the range of 300-600 $\mathrm{nm}$. The amount of $\mathrm{AlCl}_{3}$ solution was substituted by the same amount of water in blank. For quantitative analysis, quercetin (concentration range of $50-500 \mu \mathrm{M})$ was chosen as the reference compound (Fig. 1) as it is widely found in plants and the measurements were done at $425 \mathrm{~nm}$.

Procedure 2: Of the test solution (standard or sample), $1 \mathrm{~mL}$ was mixed with $0.3 \mathrm{~mL}$ of $\mathrm{NaNO}_{2}(5 \%, w / v)$ and after $5 \mathrm{~min}, 0.5 \mathrm{~mL}$ of $\mathrm{AlCl}_{3}(2 \%, w / v)$ was added. Flavonoid standard solutions of $100 \mu \mathrm{M}$ were used. A sample was mixed and 6 min later was neutralized with $0.5 \mathrm{~mL}$ of $1 \mathrm{M} \mathrm{NaOH}$ solution. The mixture was left for $10 \mathrm{~min}$ at room temperature and then subjected to spectral analysis in the range of $300-600 \mathrm{~nm}$ against the blank, where $\mathrm{AlCl}_{3}$ solution was substituted by water. Catechin (in the $50-500-\mu \mathrm{M}$ concentration range) was the standard of choice for the expression of results at $510 \mathrm{~nm}$.

\section{Folin-Ciocalteu Assay}

One millilitre of sample was introduced into test tubes followed by $0.1 \mathrm{~mL}$ of Folin-Ciocalteu's reagent and $0.9 \mathrm{~mL}$ of water. The tubes were allowed to stand for $5 \mathrm{~min}$. At the end of this period, $1 \mathrm{~mL}$ of sodium carbonate $(7 \%, w / v)$ and $0.4 \mathrm{~mL}$ of water were added and $30 \mathrm{~min}$ more were allowed for stabilization of the blue colour formed. The absorbance was measured at $765 \mathrm{~nm}$. The data were expressed as gallic acid equivalent. All determinations were carried out in triplicate. 
Fig. 1 Chemical structures of the studied flavonoids<smiles>O=c1cc(-c2ccccc2)oc2ccccc12</smiles>

Flavonoid basic structure<smiles>[R]c1c(O)ccc(-c2oc3cc(O)cc(O)c3c(=O)c2O)c1[R]</smiles>

Flavonols

Quercetin, $\mathrm{R}_{1}=\mathrm{H}, \mathrm{R}_{2}=\mathrm{OH}$

Morin, $\mathrm{R}_{1}=\mathrm{OH}, \mathrm{R}_{2}=\mathrm{H}$

Kaempferol, $\boldsymbol{R}_{1}=\boldsymbol{R}_{2}=\mathrm{H}$<smiles>[R]c1ccc(C2CC(=O)c3c(O)cc(O)cc3O2)cc1[R]</smiles>

Flavanones

Naringenin, $\mathrm{R}_{1}=\mathrm{H}, \mathrm{R}_{2}=\mathrm{OH}$

Hesperetin, $\mathrm{R}_{1}=\mathrm{OH}, \mathrm{R}_{2}=\mathrm{OCH}_{3}$<smiles>[R]c1ccc(-c2cc(=O)c3c(O)cc(O)cc3o2)cc1[R]</smiles>

Flavones

Chrysin, $\mathrm{R}_{1}, \mathrm{R}_{2}=\mathrm{H}$ Apigenin, $\mathrm{R}_{1}=\mathrm{H}, \mathrm{R}_{2}=\mathrm{OH}$ Luteolin, $\mathrm{R}_{1}=\mathrm{OH}, \mathrm{R}_{2}=\mathrm{OH}$<smiles>[R]c1cc(C2Oc3cc(O)cc(O)c3CC2O)cc([R])c1[R]</smiles>

Flavan-3-ols

Catechin, $\mathrm{R}_{1}=\mathrm{OH}, \mathrm{R}_{2}=\mathrm{OH}, \mathrm{R}_{3}=\mathrm{H}$ Epicatechin, $\mathrm{R}_{1}=\mathrm{H}, \mathrm{R}_{2}=\mathrm{OH}, \mathrm{R}_{3}=\mathrm{OH}$

\section{Results and Discussion}

\section{Model Solutions}

In the literature data for determination of total flavonoid content, procedure 1 was applied in the presence of acid, acetate salts or without addition of any reagent (Table 1). To check the effect of this reaction environment, we compare the spectra for quercetin as a model compound obtained in the presence of $\mathrm{HCl}$, acetate salts $\left(\mathrm{CH}_{3} \mathrm{COONa}\right.$ and $\mathrm{CH}_{3} \mathrm{COONH}_{4}$ ) and without them. In each case, the same amount of additives was used. As could be seen from Fig. 2, the spectra of Al-quercetin complex in the absence (water) and presence of both acetate salts show a strong absorption peak at 425-430 nm, which supposed to be constituted of two quercetin molecules bound to an aluminium ion (Cornard and Merlin 2002). Denni and Mammen (2012) reported $\lambda_{\max }$ for this complex at $426 \mathrm{~nm}$ in the presence of $\mathrm{CH}_{3} \mathrm{COOK}$ while without addition of acetate at $445 \mathrm{~nm}$. However, Alkaempferol complex exhibited in their work similar maximum absorbance (at $424 \mathrm{~nm}$ ) in the presence and absence of
$\mathrm{CH}_{3} \mathrm{COOK}$. Our studies confirmed that the addition of acetate salts (in the form of $\mathrm{CH}_{3} \mathrm{COONa}$ or $\mathrm{CH} 3 \mathrm{COONH}_{4}$ ) is not necessary as in the presence and absence of them similar absorbance values were recorded at the wavelength recommended for optical density measurement in procedure 1 . In acidic media, the disappearance of absorbance at $369 \mathrm{~nm}$ from quercetin ligand was not completely and very little of quercetin-Al complex of 1:1 stoichiometry is formed ( $\lambda_{\max }$ $425 \mathrm{~nm})$.

The reaction time interval for this reaction varied in literature in the range of 2-60 min. However, our studies showed that this parameter was not so important (data not shown). Thus, for the rest of the measurements using procedure 1, absorbance was measured after $10 \mathrm{~min}$ of the addition of $\mathrm{AlCl}_{3}$ without acetate salt.

The applicability of the aluminium-flavonoid complexation reaction according to procedure 1 was examined for other compounds from different classes of that family (Fig. 3). Flavonols (quercetin, morin, kaempferol and rutin) exhibited the maximum absorbance at $415-425 \mathrm{~nm}$, the wavelength range used for optical density measurements under these 


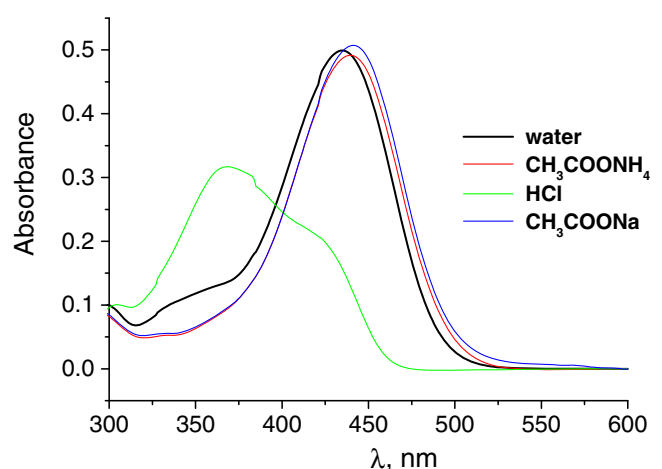

Fig. 2 The absorption spectra of quercetin $(100 \mu \mathrm{M})$ in the presence of $\mathrm{AlCl}_{3}(2 \%, w / v)$ and different reaction environment

conditions, with the lowest absorbance value for kaempferol. Flavonols are formed complexes with C-3 and C-5 hydroxyl groups and additionally with the dihydroxyl groups in $\mathrm{B}$ ring. It was reported that any blockage of the hydroxyl group by glycosylation in C-3 position prevents chelation with Al(III) (Denni and Mammen 2012). However, in our studies, rutin (quercetin-3-O-rutinosid) and quercetrin (quercetin-3-Orhamnoside) exhibited maximum absorbance at similar wavelength as their aglycone form.

Flavone luteolin formed the complexes that showed a strong absorption at $405-420 \mathrm{~nm}$, while the $\lambda_{\max }$ for the complexes formed by chrysin and apigenin, which have not shown the catechol moiety in B ring, were at $377 \mathrm{~nm}$. Similar results were observed earlier (Denni and Mammen 2012; Chang et al. 2002). Flavonones (naringenin and hesperetin) and their glycosides (naringin and hesperidin) in the presence of Al(III) exhibited maximum absorbance at 375-379 $\mathrm{nm}$. Although they can form complexes with C-5 hydroxyl group, the absorbance around $420 \mathrm{~nm}$ is too low for quantitative determination. Our results showed that the complexes formed with catechins had the maximum absorbance around $300 \mathrm{~nm}$, what confirmed earlier study (Kumamoto et al. 2001). Thus, their high contents in tea infusions or wine samples do not participate in total absorbance measured around $400 \mathrm{~nm}$. Examination of the obtained results for different flavonoids indicates that procedure 1 can be only used to determine flavonol contents and from flavone subgroup-luteolin.

Procedure 2 (in the presence of $\mathrm{NaNO}_{2}$ ), when the absorbance is measured at $510 \mathrm{~nm}$, seems to be only selective for rutin, luteolin and catechins (Fig. 3). In the presence of 5hydroxy-4-keto groups (rutin, luteolin), complexation via a catecholic moiety in B ring seems to be diminished under reaction conditions of this procedure as lower absorbance values were recorded. In our study, catechins exhibited maximum absorbance at $457-465 \mathrm{~nm}$. Similar results were obtained for epigallocatechin-3-gallate (EGCG), the major polyphenolic constituent of green tea (data not shown). Procedure 2 is much less selective for determination of flavonoids in comparison with the procedure 1 , as also non-flavonoid compounds can bear catecholic moieties. For example, chlorogenic acid, the most abundant in fruits and vegetables, exhibited considerable absorbance at $510 \mathrm{~nm}(0.240)$, while under procedure 1 at $435 \mathrm{~nm}$ the measurement was negligible (data not shown). However, the effect of the presence of other groups of phenolic compounds is not considered in the works applying this procedure (references from Table 1).

\section{Natural Samples}

The spectra of natural samples after addition of $\mathrm{Al}(\mathrm{III})$ are very rarely shown in the published papers regarding the use of the aluminium chloride reaction for determination of total flavonoid content. In a few works, only the spectra for some flavonoids (Matyuschenko and Stepanova 2003; Denni and Mammen 2012; Fernandes et al. 2012) or the absorbance values for standard compounds under applied experimental conditions could be found (Chang et al. 2002). Figure 4 shows some examples of the absorption spectra of studied natural samples after reaction with $\mathrm{AlCl}_{3}$ (without acetate salt) using different procedures. Under conditions in procedure 1, herbal tea infusion of St. John's wort exhibited the absorbance peak characteristic for flavonoids and luteolin (from flavanones family), while for green and fruit tea infusions as well as for orange juice sample, the maximum is more shifted in UV region (390-400 nm). These samples contain significant amount of flavonones (Pękal et al. 2011a; Pękal et al. 2013); however, their contribution in absorbance value measured above $400 \mathrm{~nm}$ in procedure 1 is very low. Under conditions used in procedure 2 , sample of orange juice did not exhibit absorbance above $500 \mathrm{~nm}$. Among other studied samples, for green tea infusion, the highest absorbance value at 510 was recorded.

The studied two procedures for total flavonoid content were applied to several natural food samples. Absorbance measurements in both procedures at 425 and $510 \mathrm{~nm}$, respectively, were corrected by subtracting initial sample absorbance. The obtained results presented in Table 2 could be put in the following orders in terms of their flavonoid content:

Procedure 1: fruit tea $<$ orange juice $\sim$ apple juice $<$ chamomile $<$ red wine $<$ green tea $<$ black tea $<$ St. John's wort.

Procedure 2: orange juice $<$ chamomile $<$ apple juice $<$ fruit tea $<$ black tea $<$ St. John's wort $<$ red wine $<$ green tea.

It should be noted that the order for procedure 2 when the absorbance was recorded at $470 \mathrm{~nm}$ (where some flavonoid compounds exhibit also significant absorbance) is similar to that measured at $510 \mathrm{~nm}$. Therefore, the positions of sample in the above rows depend on the procedure used for determination of the so-called total flavonoid content. For green tea infusion, characterized by the presence of large amounts of flavan-3-ols (Pękal et al. 2011b), the highest results were obtained under the conditions used in procedure 2 . These 
Fig. 3 The absorption spectra of flavonoids from different classes in the presence of $\mathrm{Al}(\mathrm{III})$ recorded after applying different procedures
Procedure 1

Procedure 2

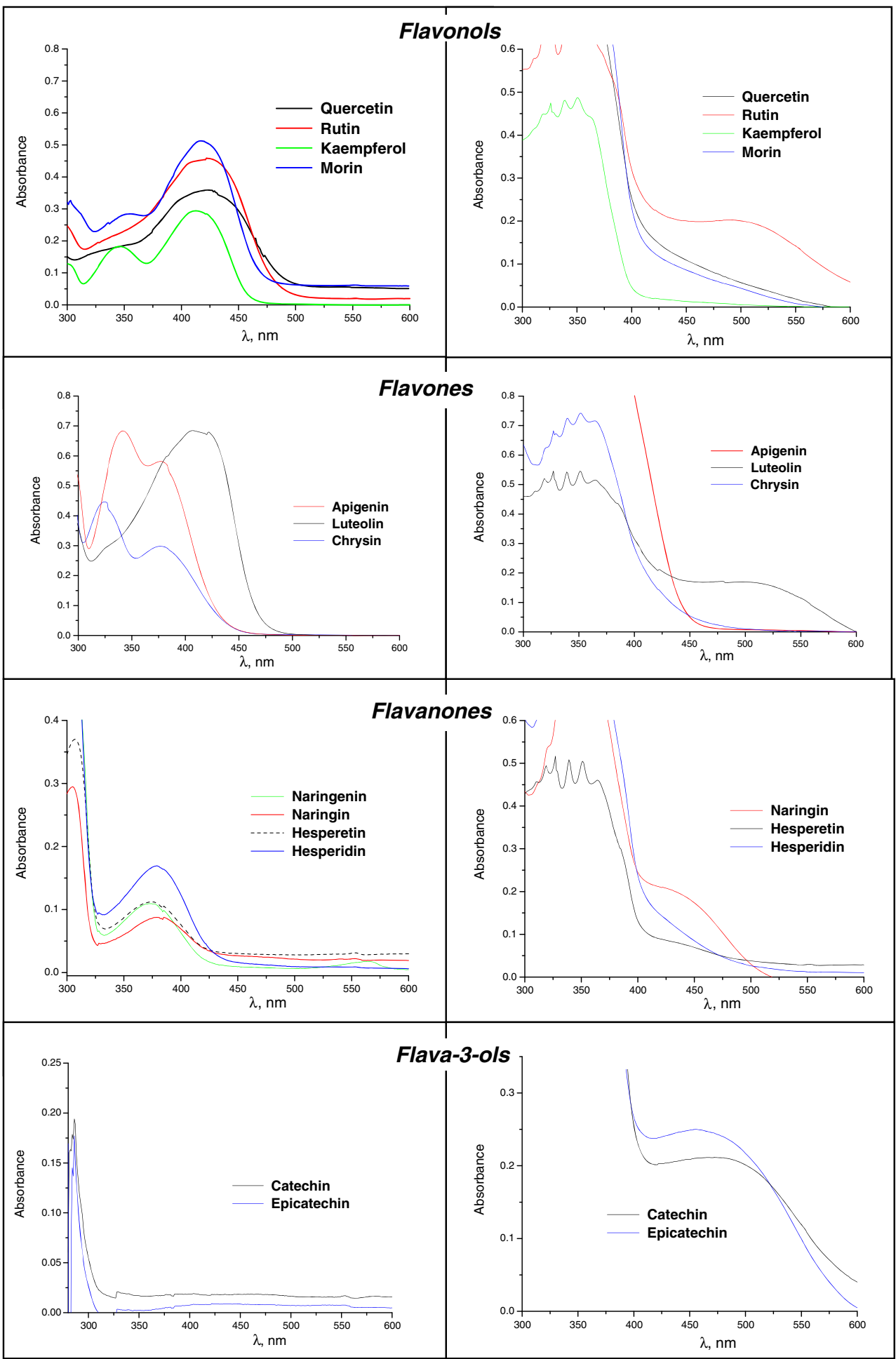

compounds do not participate in total absorbance measured at 425 nm (Fig. 3). Catechin, epicatechin, quercetin, rutin, transresveratrol, anthocyanins as well as gallic acid, caffeic acid and $p$-coumaric acid are the major polyphenols in red wines (Muñzoz et al. 2008; Porgali and Büyüktuncel 2012). From the other side, fruit tea and juices contain mainly flavonones (Gattuso et al. 2007) and these compounds contribute in the measurements in both procedures to a small extent. The studied samples are quite different in the composition of phenolic compounds. 
Fig. 4 The absorption spectra of natural samples after reaction with $\mathrm{AlCl}_{3}$ applying procedure 1 and procedure 2

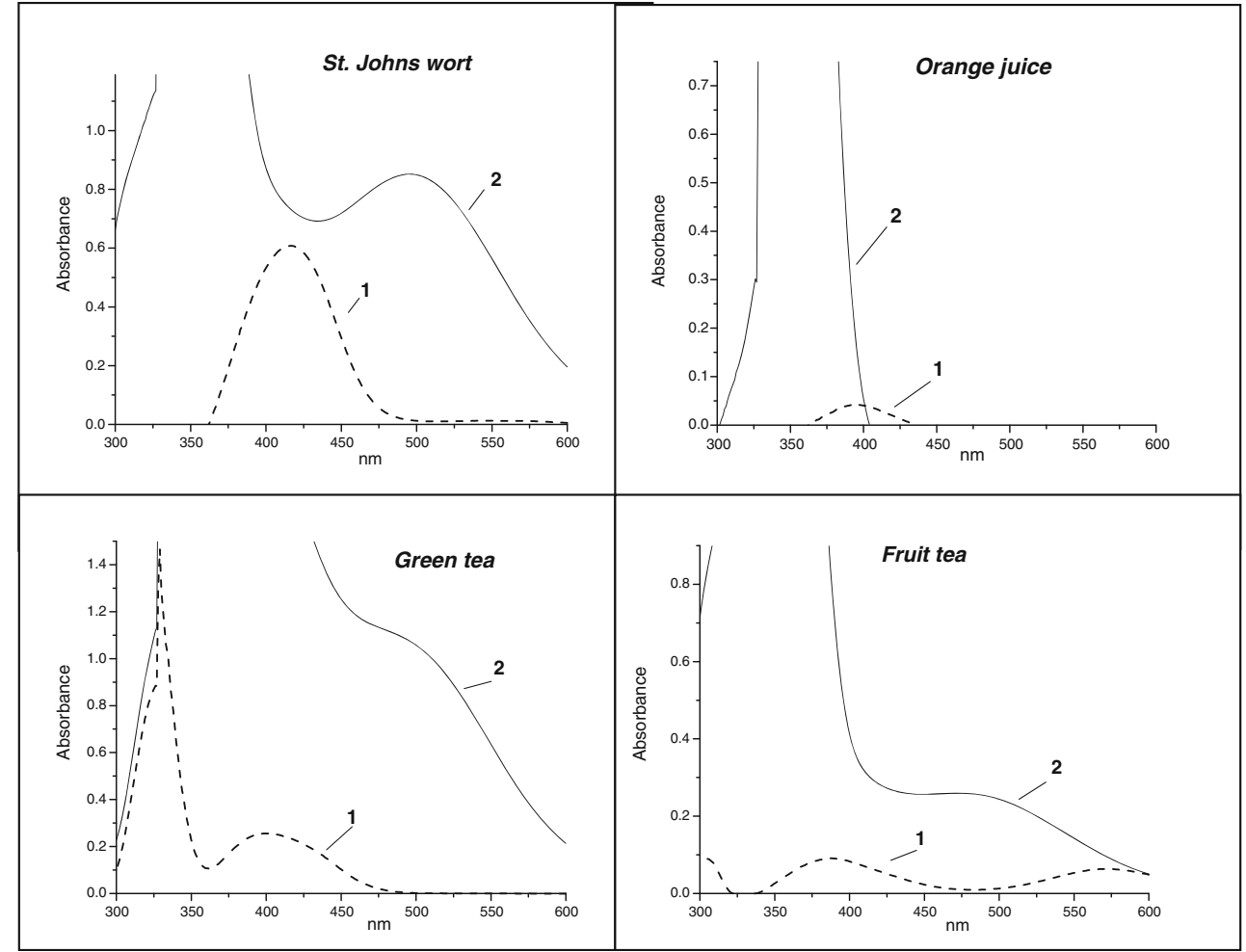

For the examined samples, assessment of total phenolic content was also carried out using the widely accepted FolinCiocalteu (FC) method (Table 2). This assay is based on a non-specific phenol oxidation reaction in alkaline medium by the two strong inorganic oxidants (phosphotungstic and phosphomolibdic acids) but it gives different responses to different phenolic compounds, depending on chemical structures (Moon and Shibamoto 2009). Moreover, the FC reagent could simultaneously oxidize several non-phenolic organic compounds as well some inorganic substances to give elevated apparent phenolic content. Thus, actually, it shows the total

Table 2 Total flavonoid content (Al(III) complexation reaction) and total phenolic content (FC assay) in studied samples obtained by different procedures

\begin{tabular}{lccc}
\hline & \multicolumn{2}{c}{ Al(III) complexation reaction } & \multirow{2}{*}{ FC assay } \\
\cline { 2 - 3 } Sample & $\begin{array}{l}\text { Procedure 1 } \\
\mu \text { M of quercetin }\end{array}$ & $\begin{array}{l}\text { Procedure } 2 \\
\mu \text { M of catechin }\end{array}$ & $\mu \mathrm{M}$ of gallic acid \\
\hline Red wine & $7.4 \pm 0.4$ & $613 \pm 30.6$ & $912 \pm 43.7$ \\
Apple juice & $1.8 \pm 0.1$ & $63.0 \pm 3.1$ & $110 \pm 5.4$ \\
Orange juice & $1.5 \pm 0.08$ & $1.5 \pm 0.1$ & $258 \pm 10.7$ \\
St. John's wort & $89.2 \pm 4.5$ & $559 \pm 27.9$ & $394 \pm 18.9$ \\
Chamomile & $5.0 \pm 0.3$ & $19.5 \pm 1.0$ & $21.7 \pm 0.9$ \\
Black tea & $28.7 \pm 1.4$ & $376 \pm 18.5$ & $834 \pm 40.8$ \\
Green tea & $25.8 \pm 1.2$ & $684 \pm 34.1$ & $1,214 \pm 61$ \\
Fruit tea & $0.40 \pm 0.002$ & $131 \pm 6.5$ & $180 \pm 8.5$ \\
\hline
\end{tabular}

reducing capacity, which is often correlated with the antioxidative activities of a given sample. The highest values in FC assay were obtained for green tea, red wine and St. John's wort samples, and the lowest for chamomile aqueous extract. The correlation between the data from FC assay and procedure 1 in $\mathrm{Al}(\mathrm{III})$ complexation reaction was not significant $\left(R^{2}=0.140\right)$, while the respective correlation with procedure 2 was much higher $\left(R^{2}=0.862\right)$. Many components of the studied natural samples, such as phenolic acids, bear catecholic moieties and contribute to the total absorbance measurement either in FC method and procedure 2, but not under the conditions used in procedure 1. Procedure 1 seems to be more specific for flavonols content.

\section{Conclusion}

Spectrophotometric assay based on aluminium complex formation is one of the most commonly applied procedure for determination of total flavonoid content in food or medicinal plant samples. Two widely applied procedures (with and without $\mathrm{NaNO}_{2}$ ) were examined for several compounds from different classes of flavonoid family and for natural samples. Both these methods did not react uniformly, which indicates that they are inadequate for evaluation of total flavonoid content in unknown samples. The procedure in the presence of $\mathrm{NaNO}_{2}$ in alkaline medium seems to be specific for rutin, luteolin and catechins. However, also other phenolic acids 
exhibit considerable absorbance at $510 \mathrm{~nm}$. Procedure conducted in neutral media (without $\mathrm{NaNO}_{2}$ ) can be only used to determine the content of flavonols and luteolin (from flavones family).

Conflict of Interest Anna Pękal has no conflict of interest. Krystyna Pyrzynska has no conflict of interest. Our article does not contain any studies with human or animals subjects.

Open Access This article is distributed under the terms of the Creative Commons Attribution License which permits any use, distribution, and reproduction in any medium, provided the original author(s) and the source are credited.

\section{References}

Barnum DW (1977) Spectrophotometric determination of catechol, epinephrine, dopa, dopamine and other aromatic vic-diols. Anal Chim Acta 89:157-166

Chang CC, Yang MH, Wen HM, Chern JC (2002) Estimation of total flavonoid content in propolis by two complimentary colorimetric methods. J Food Drug Anal 10:178-182

Chen L, Ding L, Yu A, Yang R, Wang X, Li J, Jin H, Zhang H (2007) Continuous determination of total flavonoids in Platycladus orientalis (L.) Franco by dynamic microwave-assisted extraction coupled with on-line derivatization and ultraviolet-visible detection. Anal Chim Acta 596:164-170

Christ B, Müller KH (1960) Zur serienmaessigen Bestimmung des Gehaltes an Flavonol-Derivaten in Drogen. Arch Pharm 293: 1033-1042

Cimpoiu C, Cristea M, Hosu A. Sandru M, Seserman L (2011) Antioxidant activity prediction and classification of some teas using neutral networks. Food Chem 127:1333-1328

Cornard JP, Merlin JC (2002) Spectroscopic and structural study of complexes of quercetin with Al(III). J Inorg Biochem 92:19-27

Cvek J, Medić-Sarić M, Jasprica I, Zuboćić S, Vitali S, Mornar A, Vedrina-Dragojević I, Tomić S (2007) Optimisation of an extraction procedure and chemical characterisation of Croatian propolis tinctures. Phytochem Anal 18:451-459

Denni M, Mammen D (2012) A critical evaluation on the reliability of two aluminium chloride chelation methods for quantification of flavonoids. Food Chem 135:1365-1368

Eghdami A, Sadeghi F (2010) Determination of total phenolic and flavonoids contents in methanolic and aqueous extract of Achillea Millefolium. Org Chem J 2:81-84

Fernandes AJD, Ferreira MRA, Randau KP, de Souza TP, Soares LA (2012). Total flavonoid content in the raw material and aqueous extractives from Bauhinia monandra Kurz (Caesalpiniaceae). Scientific World Journal article ID:923462.

Gattuso G, Barreca DD, Gargiulli C, Leuzzzi U, Caristi C (2007) Flavonoid composition of citrus juices. Molecules 12:1641-1673
Ghasemzadeh A, Jaafar HZE, Rahmat A (2010) Antioxidant activities, total phenolic and flavonoids content in two varieties of Malaysia young ginger (Zingiber officinale Roscoe). Molecules 15:4324 4333

Gouveia S, Castilho PC (2011) Antioxidant potential of Artemisia argentea L'Hér alcoholic extract nd its relation with the phenolic composition. Food Res Inter 44:1620-1631

Horszwald A, Julien H, Andlauer W (2013) Characterisation of Aronia powders obtained by different drying processes. Food Chem 141: 2858-2863

Ivanova V, Stefanova M, Cinnici F (2010) Determination of the polyphenol contents in Macedonian grapes and wines by standardized spectrophotometric methods. J Serb Chem Soc 75:45-59

Jaiswal AK, Abu-Ghannam N (2013) Degradation kinetic modelling of color, texture, polyphenols and antioxidant capacity of York cabbage after microwave processing. Food res Inter 53: $125-133$

Kumamoto M, Sonda T, Nagayama K, Tabata M (2001) Effects of pH and metal ions on antioxidative activities of catechins. Biosci Biotechnol Biochem 65:126-132

Licina BZ, Stefanovic OD, Vasic SM, Radojevic ID, Dekic MS, Comic LR (2013) Biological activities of the extracts from wild growing Origanum vulgare L. Food Control 33:498-504

Mãrghitas LA, Dezmirean D, Moise A, Bobis O, Laslo L, Bogdanov S (2009) Physici-chemical and bioactive properties of different floral origin honeys from Romania. Food Chem 112:863-867

Matyuschenko NV, Stepanova TA (2003) Quantitative determination of the total content of flavonoids in the new phytopreparation Elima. Pharm Chem J 37:261-263

Moon JK, Shibamoto T (2009) Antioxidant assays for plant and food components. J Agri Food Chem 57:1655-1666

Muñzoz S, Mestres M, Busto O, Guash J (2008) Determination of some flavan-3-ols and anthocyanins in red grape seed and skin extracts by HPLC-DAD: validation study and response comparison of different standards. Anal Chim Acta 628:104-110

Ordonez AAL, Gomez JD, Vattuone MA, Isla MI (2006) Antioxidant activities of Sechium edule (Jacq.) Swartz extracts. Food Chem 97: $452-458$

Pękal DP, Biesaga M, Pyrzynska K (2011a) Evaluation of the antioxidant properties of fruit and flavoured black teas. Eur J Nutr 50:681-688

Pękal DP, Biesaga M, Pyrzynska K (2011b) Screening of the antioxidant properties and polyphenol composition of aromatised green tea infusions. J Sci Food Agric 92:2244-2249

Pękal A, Biesaga M, Pyrzynska K (2013) Trace metals and flavonoids in different types of tea. Food Sci Biotechnol 22:925-930

Porgali E, Büyüktuncel E (2012) Determination of phenolic composition and antioxidant capacity of native red wines by high performance liquid chromatography and spectrophotometric methods. Food Res Inter 45:145-154

Praveen KR, Awang B (2007) Antioxidant activity, total phenolic and flavonoid content of Morinda citrifolia fruit extracts from various extraction processes. J Eng Sci Technol 2:70-80

Zhang DY, Luo M, Wang W, Zhao CJ, Gu CB, Zu YG, Fu YJ (2013) Variation of active constituents and antioxidant activity in pyrola [P. incarnata Fisch.] from different sites of Northeast China. Food Chem 141:2213-2219 